\title{
Research on the Strategy of Electronic Documents Management of Universities Based on Digital Campus
}

\author{
Shichen Chen*
}

\author{
Archives, Quanzhou Normal University, Quanzhou, China \\ *Corresponding author. Email: 844149688@qq.com
}

\begin{abstract}
With the rapid development of digital technology, the current society has entered the era of digital transformation. The author tried to find better ways based on digital campus to improve the level of electronic documents management of universities. But at present there are still many problems of electronic documents management. The main ways are perfecting the mechanism, strengthening the construction of information resources, further perfecting and implementing the standard systems of electronic documents management, enhancing archives information security, improving the level of service, adopting outsourcing service mode. The new ideas, new technologies and new means of digital campus are powerful support for electronic documents management.
\end{abstract}

Keywords: University, Digital campus, electronic documents, management strategy

\section{INTRODUCTION}

With the increasing matureness and widespread of EPC system network, mobile Internet, blockchain and AR/VR, etc. digitization technology is not only completely changing the life style of human society but also assaulting the traditional working modes. The increasingly developed digitization technology is gradually changing the traditional teaching, research, management and life in universities at the same time. Chinese Education Modernization 2035 issued by the CPC Central Committee and the State Council enhances that accelerating the educational reform of informatization age and founding intelligent campus will become the focus of education in the future. In fact, you could say that speeding up digital transformation and promoting the construction of intelligent campus is the powerful support for promoting the quality of higher education. Being one of the important parts of universities work, archival work is being tempestuously influenced without exception. Digital campus has brought a profound reform in all the objects, modes, contents and ideas of archives. With the advent of the digital age, the traditional paper documents are gradually replaced by the electronic documents which are generated in digital equipment and environment and stored in electronic devices such as disk, CD, etc. on digital form. In 1997, International Archives Council merged two sub-organizations, Electronic Documents Committee and Current documents Committee, into one named Electronic and Other Documents Committee. It means the dominant medium of archives has changed from paper documents to electronic documents in international archives academic field. Recently, the electronic documents which record the talent cultivation, scientific research, management activities and life information of universities have gradually become the main body of archival work and conversely raise the level of digital campus.

\section{PROBLEMS OF ELECTRONIC DOCUMENTS MANAGEMENT OF UNIVERSITIES AT PRESENT}

The current society has entered the era of digital transformation and digital construction are valued more in universities than before. The new ideas, new technologies and new means of digitalization appear one after another. But till now there are some problems of electronic documents management of universities, both macroscopic strategy and microcosmic technology, need to be solved.

\subsection{The Electronic Documents Information Management Is Out of Control}

For a long time, people's awareness of archives still stays on the category of paper documents while unaware of the importance, particularity and value of electronic documents. Many universities have not brought the electronic documents into the scope of archives management and the collection and storage of electronic documents have not been systematically carried out, not to mention the development and implementation of standardized electronic document management system. In fact, the authenticity, effectiveness, integrity and usability of electronic documents cannot be guaranteed because of unscientific management. Due to the lack of overall management, the departments shuffle each other about their responsibilities that leads to severe loss and most electronic documents still remain in forming units or 
individuals. Although many universities have invested huge personnel, funds and equipment in the construction of digital campus and achieved initial results, the electronic documents management is still decentralized. Now in most universities, different business systems have no integration and the connectivity among them is poor. Most electronic documents are kept separately in the business systems where they are produced, such as teaching system, scientific research system, student work system and OA system and that will bring risks to electronic documents management.

\subsection{The Security of Electronic Documents Is Outstanding}

From the date of generation, the electronic documents always face all kinds of dangers, such as quality damage and life reduction for inadequate storage facilities, irreparable damage for natural disaster. Some technical and personnel factors leave the long-term effective preservation of electronic documents imperceptible but serious security exposure.In addition to these common risks, the electronic documents will face other risks from internet technology. Being an open and Interactive platform, network brings great convenience to people's production and life and many risks at the same time. On internet, the electronic documents can be read and even modified anytime, anywhere by anyone. Malicious attacks and virus entry will tamper and damage the information. Digital campus brings many new application system but the incompatibility leads the chaos of electronic documents.Even in universities with lots of high-quality talents, most archivists and other staff lack security consciousness of electronic documents and security knowledge of network. So in the progress of generation, transmission and management the electronic documents are often damaged by hackers.

\subsection{The Level of Whole Process Control of Electronic Documents Is Low}

Different from paper documents management, the most important feature of electronic documents management is system control while not carrier control. With the construction of digital campus, universities implement whole-process management to the lifecyle of generation, arrangement, transmission, storage and destruction of electronic documents with scientific management mechanism, normative management standards, professional management system. The lifecyle of a document is the process of generation, development, and disappear when it is being created, distributed, processed, preserved, used and destructed.[1] The mode of traditional paper document management emphasizes that different stages of the document lifecycle should be managed differently and its focus is back-end control. But the mode of electronic documents management focuses on front control. The electronic documents are designed and formed according to uniform specifications and standards and archived and stored in various business systems through the network. The electronic documents are transferred to the archives management system in the end and become so-called Electronic Records.

\subsection{The Level of Development and Utilization of Electronic Documents Information Resources Is Low}

For a long time, we didn't pay enough attention to the work of archives appraisal and opening for traditional idea. We overemphasis on the confidentiality and preservation of archives while ignoring the opening and utilization. The construction of archives resources in most universities still value the collection instead of utilization. Along with the overdo of security work, the service function of archival holding is maximally restricted.

Now most departments of universities have computers and appropriative storage devices such as compact disks, tapes and hard disks, but professional electronic documents management system is seldom equipped with. Without professional electronic documents management system for secure and efficient standardized management to deal with massive electronic documents, these problems of catalog setting, classification archiving, metadata capture, automatic backup cannot be resolved well. Even the electronic documents are saved in the computer systems, they cannot have scientific, efficient and reasonable development and utilization.

\section{REASONS ANALYSIS}

\subsection{Reasons of Ideas}

In universities many people besides archive workers do not treat electronic documents as formal documents and ignore their archives functions. People are often unaware of the value of information assets of electronic documents at the digital age, even while identifying the archival value of electronic documents. Some archives workers resistance informatization mode of archives because they think the safety reduction is not high. At the link of collection, many universities follow the same management pattern of paper documents management: unity of directions, hierarchy management, directional collection and scheduled handover. This mode makes for centralized and unified management, but cannot adapt itself to such conditions of huge number and specialties of instantaneity, convenience, flattening of electronic documents. In addition, most universities adopt the management mode of double-track or double-set which paper documents and electronic documents coexist because of lack of overall plan or awareness of benefit. The mode of double-track is coexistence of both the two progresses of electronic 
documents and paper documents. The mode of double-set is required to have electronic documents saved as soon as paper documents.[2]The two traditional modes look safe but cause awful waste of financial, human, and material resources while not realizing high efficiency of digital campus.

\subsection{Reasons of Working Mechanism}

Although electronic documents have become the main recording form of teaching, science and research and management of universities, most universities have no sturdy and strong coordination mechanism for electronic documents management. The mechanisms of electronic documents management in some universities are defective or not fully implemented in actual work. Some universities follow the mechanisms of paper documents for electronic documents management, so the traditional mode of production, transmission and storage cannot adapt itself to the fast-growing digital technology.

\subsection{Reasons of Specifications and Standards}

Scientific working mechanism based on perfect specifications and standards has rules to follow with construction of legislation, standardization and normalization. There are a series of laws and standards on electronic documents management in China now. But there are problems of bull management, overlapping management and simplicity of management, etc. because of different departments and poor implementation. For example, the regulations of metadata are often different. In China, Code for Management of Electronic Construction Record and Archives, Metadata of Pratacultural Resource Iinformation and Core Metadata Standard for Land Resources Information were issued by different departments and different names, format, standards and procedure remain stuck of unified standards, unified management, data exchange and information sharing. Even in the archives academic circle, some basic terminology of electronic documents were not standardized for a long time.For instance, the name of electronic documents itself was not standardized in different standards. Electronic Signature Law in China issued on August 28, 2004 called it Data Electronic Text. Interim Procedures for Archiving Management of Electronic Official Document which was issued on September 1, 2003 and revised on December 14, 2018 by National Archives Administration of China called it Electronic Official Document. Requirements for Optical Disk Storage, Archiving and Archival Management of CAD Electronic Records (GB/T17678.1-1999) called it Electronic Records. Different names especially English names will make archives workers misunderstand the concepts and go against international academic and business exchanges and cooperation.

In actual work in universities, there are problems caused by different standards, such as weak implementation on national standards, lack of standards on concrete business procession. Besides, what kind of documents should be digitally processed, format requirements for electronic documents, storage standards, etc. In brief, incomplete standards and weak implementation will cause the confusion of electronic documents management.

\subsection{Reasons of Infrastructure}

Electronic documents are generated, transmitted and stored on computers, so electronic documents management are inseparable from computer hardware and software equipment. You might even say computers are the premise and foundation of generation and management of electronic documents. The hardware equipment mainly include computers, scanners, servers, disks, CD, etc. The software mainly include information processing systems, databases and related software programs, etc. With the development of digital campus construction, the hardware has been basically resolved or to a certain extent, except some universities with relatively poor school conditions. The software is the main problem of infrastructure of electronic documents management in universities. Compared with paper documents management, the most important feature of electronic documents management is system control while not medium control. That means information processing system is the decisive factor of electronic documents management. The current information processing systems in most universities are built separately by different departments according to their business needs, such as office automation system, teaching management system, financial management system, student management system, library management system, file management information system, etc. These systems can basically meet the requirements of some certain job, some information isolated islands are formed in the environment of digital campus, however. The data exchange and information sharing cannot be realized because these systems are short of transverse interconnection. To fill that gap the universities must increase investment to build professional information systems and break down barriers between different systems.

\section{THE SOLUTIONS TO ELECTRONIC DOCUMENTS MANAGEMENT OF UNIVERSITIES BASED ON DIGITAL CAMPUS}

Economic construction will be transformed at some point and it's the same to archives work. It's proposed in The Outline of the 13th Five-Year Plan for National Archives Cause Development that modernization of archives management with the core of informatization will be elementarily realized during 2020. That is an important goal of transformation and upgrading of archives cause.[3]The archives informatization management is an 
important part of construction of digital campus in universities. With the continuous improvement of the level of digital campus construction, the archives cause of universities should meet the needs of economic and social development by promoting the electronization, digitization and networking of archives management and realize the transformation and upgrading of itself. How to adapt to the new environment, to take strong, long-term and effective measures to cope with the great challenges which the electronic documents management will face? All above have become major problems that cannot be avoided and need to be solved urgently.

\subsection{Perfecting the Work Mechanism}

Facing the electronic documents of extensive sources, large quantity, multi-format and rapid growth, strengthening the top-level design and establishing and perfecting the work mechanism are key tasks of electronic documents management of universities. The process of formation, circulation, capture, archiving and utilization of electronic documents in universities involve all the business departments and secondary colleges, so the archives administration should actively take the lead to strengthen the cooperation among document formation departments, information technology departments and archives departments. Only then can the efficiency of electronic documents management be increased. A full set of systems and measures of electronic documents management which are made based on the rules of higher education, Interim Measures for the Archiving and Management of Electronic Official Documents, Specification on Electronic Documents Archiving and Electronic Records Management and combined with the actual situation of universities must be established to manage formation, arrangement, archiving, development and utilization of electronic documents in universities as a whole. Only can the integrated management of electronic documents be realized. The integrated management of electronic documents of universities based on the digital platform regards the progress of formation, dealing and archiving of electronic documents with preservation value from all business departments as an organic whole and realizes a whole process management.[4]The integrated management of electronic documents is the achievements of practice and exploration of electronic documents management in universities.It can effectively achieve the best goal of management and utilization by whole process management of documents and front control of archival information.

\subsection{Strengthening the Construction of Information Resources}

The basic policy of construction of electronic information resources is the overall implementation of national archives strategy, digitalization of the stock and electronization of the increment. Two wrong ways of construction of information resources in universities must be put an end. One is blind collection short of identification, implementing full digitization of the stock with a lot of manpower and financial resources and that can lead to great wast. The other is neglect of the collection and quality control of incremental electronic documents and that can result in loss of information resources.The principle of construction of electronic information resources is striving for the best results with the least input. According to The Outline of the 13th Five-Year Plan for National Archives Cause Development, universities should perfect the work mechanism of construction of electronic information resources by implementing the systems of single-track mode and single-set system as soon as possible on the base of double-track mode and double-set system which are commonly adopted. The single-set system of electronic records means documents produced by electronic equipment are stored only in electronic form. The singletrack mode of electronic records means no longer paper files. [3]

\subsection{Further Perfecting and Implementing the Standard Systems of Electronic Documents Management}

To implement informatization management, universities must formulate relevant standards which are not only on one aspect but for whole standard systems. The standards involve not only website information system design and management software of electronic documents but also digitization of paper documents. After a long period of effort, Chinese laws, regulations and standards of electronic documents management have become increasingly mature. Interim Measures for the Archiving and Management of Electronic Official Documents was enacted by the National Archives Administration in July, 2003 and revised in December, 2018. In 2003, Management Measures for Electronic Documents Transmission was enacted by General Office of the State Council. In 2009, General Office of the CPC Central Committee and General Office of the State Council jointly promulgated Interim Measures for the Management of Electronic Documents. In addition to these, the state administrative department for standardization and other relevant administrative departments jointly enacted some industry standards and domain specifications, such as Specification on Electronic Documents Archiving and Electronic Records Management in 2016. The rules and standards above are important reference for electronic documents management and have been playing an active guiding role.

There are two main ways of standardization construction of electronic documents of universities. One is further promoting national management standards of electronic documents and implementing these standards of collecting and integration. The other is establishing various standards 
and detailed rules of implementation can be put forward in combination with the facts of universities. The standards of universities, such as Measures of Electronic Documents of Universities, Detailed Rules of Electronic Documents Archiving of Universities, Information Metadata Standards of Universities can be established. Metadata, which are data on data, are lifeblood of electronic documents management. Only the metadata caught during the whole progress of lifecyle of electronic documents can the authenticity, integrality, reliability and availability be guaranteed. Universities must pay enough attention to metadata standards in electronic documents standards. Strengthening the storage, protection, analysis and utilization of metadata to realize standardized management of progress of finding, development, organization, maintenance, open and utilization.

\subsection{Enhancing Archives Information Security}

Electronic documents may be inevitably misused, stolen, lost, affected by virus or attacked by a hacker in the progress of formation, transmission, capture, arrangement, archiving and utilization. All these raise urgent request for information security guarantee work of electronic records. Firstly, the hierarchy protection on information security and classified protection on secret-involved information system should be implemented further. The protection system of archives information system should be improved to raise the level of archives information system and network security protection. Secondly, the physical isolation of secret archives is necessary. The physical isolation can prevent all kinds of secret archives especially the personal files of teachers and students with a huge amount of information from divulgence. Thirdly, adopting modern new technology. Besides those traditional anti-counterfeiting technology, new technology must be adopted, such as bar code anti-counterfeiting, SN serial number anti-counterfeiting, two-dimensional code anti-counterfeiting, etc. Fourthly, establishing and perfecting remote backup heterostructure system of electronic documents. Remote backup heterostructure system will found a safe and high efficiency guarantee system of electronic archives by introducing advanced practical management system of electronic documents. This kind of system is a common measure to deal with nearly any risk of electronic documents.

\subsection{Improving the Level of Service}

The ultimate goal of digitization and informatization construction of universities archives is improving the level of service so the users can get the archival information through computers, network and other channels with multivariate, high efficiency and high quality service.

\subsubsection{Firstly, establishing the service platforms of archives inquiry and utilization}

Li Minghua, Director of the National Archives Administration said at 2019 National Conference of Archivists and Directors that the construction of national archives query service platform will start this year. And the users can consult the files freely at home on this platform. The short-term target is building a network platform which can accommodate comprehensive archives at various levels as many as possible. The long-term target is providing comprehensive archives at various levels of the country access to the platform and realizing consulting files countrywide.[5]The universities can build service platform of archives inquiry and utilization on the basis of digital technology for expanding the service channel and optimizing the service mode to improve the level and quality of archival services for teachers, students and the community.

\subsubsection{Secondly, playing the role of new media}

The universities should keep pace with the times to make full use of new media. The social media, such as WeChat, microblog and QQ, can be used to keep in close contact with archives users to collect their utilization demands. The system will analyze the demands and the content of archival data and accurately recommend the relevant data to the users through internet.

\subsubsection{Thirdly, building intelligent archives at the right moment}

Both National Outline for Medium- and Long-term Educational Reform and Development 2010-2020 and The Ten-Year Plan for Education Informationization 2011-2020 indicate that the construction of service-oriented intelligent campus on the base of digitization is the core mission of construction of higher education informationization. By the time of June 2019, there are 854 million netizens which is 25.98 million more than the number at the end of 2018. The internet popular rate is $61.2 \%$ which is $1.6 \%$ higher than it at the end of 2018. There are 847 million mobile phone users in China which is 29.84 million more than the number at the end of 2018. And $99.1 \%$ netizens go online by mobile phones which is $0.5 \%$ higher than it at the end of 2018. [6] In the era of Internet plus, the universities comprehensive archives should build intelligent archives platform which take network technology as the key, regard the public users as the core. The intelligent consulting, intelligent exhibition and intelligent retrieval and utilization will become a reality.

\subsection{Adopting Outsourcing Service Mode of Archive Business}


Due to the lack of archival workers at present, the essential high-quality talents, high-quality equipment and high-level technology are still understaffed in most universities. It will take a long time to solve these problems. It's an efficient optimization approach to purchasing the related business from social institutions of higher qualifications. Professor Huang Xiaoyu said that it's an inevitable choice of improving efficiency and quality of public service of archives by breaking the governmental monopoly position and releasing the governmental functions to the market and society.[7]Those universities owning good advantage can outsource some relevant work of electronic documents management to specialized companies. In this way the electronic documents management will have high effect with less investment.

\section{SUMMARY}

With the rapid development of digital technology, the digital construction has become an important symbol of the integrative evaluation of universities. The archival departments are becoming increasingly aware of the importance of electronic documents management. A series of problems gradually apparent to reveal out. In terms of these opportunities and challenges, the archival departments must try to take appropriate measures to fully develop the level of electronic documents management. Scientific management of electronic documents will help archives cause serve the teaching, research, management of universities and the society.

\section{REFERENCES}

[1] Zhang Zhengqiang, Electronic Documents

Management, the People's Liberation Army Press,

Beijing 2004.

[2] Feng Huiling, Zhao Guojun, Electronic Records Management in China: Problems and Solutions, China Renmin University Press, Beijing, 2009, pp. 27.

[3] The Outline of the 13th Five-Year Plan for National Archives Cause Development, J. China Archives, 05(2016)14-17.

[4] Shi Junfeng, etc.Study on the Integrated Management of Electronic Records in Colleges and Universities in the Cloud Computing Environment, J.Library And Information Service, 2(2014)

[5] Li Minghua, Work Report at National Conference of Archives Directors and Curators, J. China Archives, 4 (2019) 22.

[6] Information on CNNIC http://www.cnnic.net.cn/hlwfzyj/hlwxzbg/hlwtjbg/2019 08/t20190830_70800.htm.
[7] Huang Xiaoyu, Research on Archival Socialized Service, China Renmin University Press, Beijing, 2016, pp. 99. 